\title{
Improving the lubrication and anti-corrosion performance of polyurea grease via ingredient optimization
}

\author{
Guanlin REN ${ }^{1, \uparrow}$, Xiaowen SUN ${ }^{2, \dagger}$, Wen LI $^{1}$, Hao LI ${ }^{1}$, Lin ZHANG ${ }^{2}$, Xiaoqiang FAN ${ }^{2, *}$, Dongshan LI ${ }^{3}$, \\ Minhao ZHU ${ }^{1,2}$ \\ ${ }^{1}$ Tribology Research Institute, School of Mechanical Engineering, Southwest Jiaotong University, Chengdu 610031, China \\ ${ }^{2}$ Key Laboratory of Advanced Technologies of Materials (Ministry of Education), School of Materials Science and Engineering, \\ Southwest Jiaotong University, Chengdu 610031, China \\ ${ }^{3}$ State Key Laboratory of Solid Lubrication, Lanzhou Institute of Chemical Physics, Chinese Academy of Sciences, Lanzhou \\ 730000, China
}

Received: 13 January 2020 / Revised: 28 March 2020 / Accepted: 07 May 2020

(C) The author(s) 2020.

\begin{abstract}
Thickener formulation plays a significant role in the performance characteristics of grease. The polyurea greases (PUGs) were synthesized using mineral oil (500SN) as the base oil, and by regulating the reaction of diphenylmethane diisocyanate (MDI) and different organic amines. The as-prepared PUGs from the reaction of MDI and cyclohexylamine/p-toluidine exhibit the optimum physicochemical and friction-wear properties, confirming that the regulation of thickener formulation can improve the performance characteristics of grease, including friction reduction, wear, corrosion resistance, and load-carrying capacity. The anticorrosion and lubrication properties of as-prepared PUGs depend on good sealing functions and a boundary lubrication film (synergy of grease-film and tribo-chemical reaction film), as well as their chemical components and structure.
\end{abstract}

Keywords: thickener; polyurea grease (PUG); corrosion resistance; tribological properties

\section{Introduction}

With the advancement of industrial technology, mechanical equipment inevitably operates in extremely severe climate/working conditions, such as high/low temperature, sandstorms, salt spray, acid/ alkali atmospheres, high/low speeds, and loads. The resulting friction, wear, and corrosion have negative effects on the performance and service life of equipment [1-3]. Therefore, it is essential to have effective protection for improving the adverse operating conditions of mechanical equipment. Grease is a semisolid lubricant with the characteristics of lubrication and sealing [4]. Its inherent consistency and adhesiveness differ from liquid and solid lubricants, and can be applied on friction pairs without leakage due to gravity [5]. Thus, it possesses unique superiority as a corrosion-resistant material. Polyurea grease (PUG) is a potential grease that accounts for a large proportion of the high-end grease market. Compared to other greases, PUG has advantages such as oxidation stability, high/lowtemperature application, mechanical stability, antirust properties, and colloidal stability [6-8]. As a kind of a non-soap based grease, PUGs are free from the catalytic oxidation of soap base grease, thereby prolonging their service life at high temperatures [9]. PUG is a multi-phase system that disperses the polyurea thickener into liquid lubricant to form a colloidal structure. Polyurea is an important kind

$\dagger$ These authors contributed equally to this work.

* Corresponding author: Xiaoqiang FAN, E-mail: fxq@home.swjtu.edu.cn 
of thickener that is polymerized by urea compounds $[10,11]$. Based on the amount of carbamido contained in a polyurea thickener, it can be divided into diurea or tetraurea based on the proportion and structure of reactants [12]. Nitrogen atoms with lone pair electrons enhance the polarity of urea compounds, which makes the PUG possess excellent affinity with metals. However, some properties of PUG should be modified, such as the inferior shear stability and limited shelflife. Regulating the formulation of thickener is an effective way to enhance the performance of PUG. Therefore, it is imperative to improve the performance of PUG for accommodating complicated and severe operating conditions.

The thickener as a dispersed phase in grease facilitates the grease to possess a semi-solid form, acting as a seal for mechanical parts. The good compatibility between base oil and thickener contributes to the colloidal stability and hightemperature oxidation resistance [13]. The rheological properties of grease also depend on the thickener structure and concentration [14]. When grease is subjected to a certain stress, it maintains its form due to its elasticity. When the stress exceeds the yield stress, the grease begins to soften and flow because the structure of the thickener is destroyed. At this moment, the base oil is released from the network of thickener, replenishing the contact area for providing the lubrication function [15, 16]. Once the grease cannot bleed enough base oil, it is considered to be at starved conditions [17-19]. The yield stress and oil-releasing mechanism of grease strongly rely on the structure of thickener [20, 21]. Thus, thickeners with different structures depend on the physicochemical properties of grease and influence their tribological performance. The superior load-carrying capacity over lubricating oil is attributed to the existence of thickener. Thickener can be deposited or adhered on worn surfaces to separate the surfaces, and its structure plays an important role in the film thickness of grease [22]. The noise reduction performance at high-temperature conditions also depends on the structural change of polyurea thickener [23]. Therefore, the action of thickener structure for the performance of PUG can not be neglected.
Considering the importance of the thickener to the performance of grease, numerous scholars have focused on the microstructure of thickener to improve the performance of PUG. Liu and Sun [12] illustrated that there is a higher number of urea groups in the polyurea thickener molecule, and the PUG has superior performance, such as higher dropping point, lower oil separation, better shear stability, and initial wear load. Lyadov et al. [24] investigated the effect of base oil viscosity and the different lengths of hydrocarbon substituent in the diurea thickeners on the physicochemical property and the tribological performance of PUG. They revealed that the base oil viscosity and the diurea molecule with different lengths of hydrocarbon substituent have significant effects on the physicochemical properties. Maksimova et al. [13] revealed the relationship between components, rheology, and antiwear properties of PUG by regulating the type of base oil and the polyurea component with different amines. They found that a $25 \%$ dispersion of dodecylamine-based diurea in a dioctyl sebacate medium contributes to the improvement of colloidal stability and yield stress. Therefore, the polyurea thickener prepared by different organic amines has a significant influence on the properties of PUG due to the compatibility of thickener and base oil, however, this issue hardly receives attention. It is important to develop a high performing PUG by regulating organic amines to meet the operation requirement under harsh working conditions.

In this work, octadecylamine, cyclohexylamine, and p-toluidine were selected to synthesize the polyurea thickener by reacting them with diphenylmethane diisocyanate (MDI) due to their advantages in corrosion resistance, thermal stability, and chemical stability. Therefore, the formulation of PUG was regulated via the saponification reaction of the MDI and different organic amines (including onefold organic amine (octadecylamine, cyclohexylamine, p-toluidine) and their combinations in different molar ratios (1:2, 2:1, 1:1)). The performance characteristics of the as-prepared PUG were investigated in detail, especially salt spray resistance and tribological properties. The friction and corrosion 
mechanisms were explored by surface/interface analysis techniques.

\section{Experimental}

\subsection{Materials}

MDI, octadecylamine, cyclohexylamine, p-toluidine, and octadecanol used in this study were purchased from Kelong Chemical Reagent Company, China. Mineral oil (MO) was commercially obtained from the Lanzhou Refinery Company, China; ethanol and petroleum ether were also purchased from Kelong Chemical Reagent Company. All chemicals in this work were employed without further purification.

\subsection{Preparation of PUG}

The routing of PUG (onefold organic amine) is as follows: First, the base oil was heated to $120^{\circ} \mathrm{C}$ and kept warm for 5-10 min to remove moisture. Second, $60 \mathrm{wt} \%$ and $40 \mathrm{wt} \%$ base oils were offloaded into two vessels, respectively, and then heated to $80{ }^{\circ} \mathrm{C}$, completely dissolving the proportional MDI and organic amine, respectively, with continuous stirring. The organic amine was completely dissolved into the $40 \mathrm{wt} \%$ base oil. Third, the two mixtures were blended to react completely for $60 \mathrm{~min}$ at $105-125{ }^{\circ} \mathrm{C}$. Fourth, the octadecanol was added into the mixture for 10-15 $\mathrm{min}$, then the hightemperature refining was maintained for $20 \mathrm{~min}$ at $170-180^{\circ} \mathrm{C}$. Finally, after being naturally cooled to room temperature $\left(25^{\circ} \mathrm{C}\right)$, the initial grease was introduced to a three-roll mill and grounded/ homogenized three times. High-end PUGs were prepared completely. The distinctions of process routing on the combination of the two organic amines are as follows: the original base oil was separated into three parts (the proportion depends on the amount of reactants). The base oil with the dissolved organic amine was added into the MDI dissolved base oil at $20 \mathrm{~min}$ intervals. In this experiment, the base oil (MO (500SN)) accounts for $85 \mathrm{wt} \%$ of the grease with a kinematic viscosity of $97 \mathrm{~mm}^{2} / \mathrm{s}\left(40^{\circ} \mathrm{C}\right)$. The organic amines include onefold organic amine (octadecylamine, cyclohexylamine, and p-toluidine) and a combination of two organic amines in different molar ratios of 1:2, 2:1, and 1:1. The combination of two organic amines contains: octadecylamine and cyclohexylamine $(\mathrm{O}+\mathrm{C})$, octadecylamine, and p-toluidine $(\mathrm{O}+\mathrm{P})$, cyclohexylamine and $\mathrm{p}$-toluidine $(\mathrm{C}+\mathrm{P})$. Therefore, twelve kinds of PUGs were obtained. Figure 1 shows the images of as-prepared PUG via regulating organic amine. First, the diversity of color and consistency of greases originate from the thickener agents, with some differences in composition and structure via regulating the reaction of different organic amines with MDI. Second, the as-prepared PUGs have high consistency, illustrating good dispersion systems and sensitivity between the thickener and base oil. Third, the as-prepared grease has less tendency to oil separation, indicating excellent colloid stability. Therefore, these images suggest that as-prepared greases have good physicochemical performance, contributing to the excellent sealing function.

\subsection{Physicochemical properties of PUGs}

The dropping point of as-prepared grease was evaluated by a SYD-3498-I drop point tester (Shanghai Jingxi Instrument Manufacturing Co., Ltd.) following ASTM-D566. The cone penetrations were measured by a SYD-2801C lubricating grease cone penetrometer (Shanghai Changji Geological Instrument Co., Ltd.) according to GB/T 269 (ASTM D1403). The copper strip test was measured by
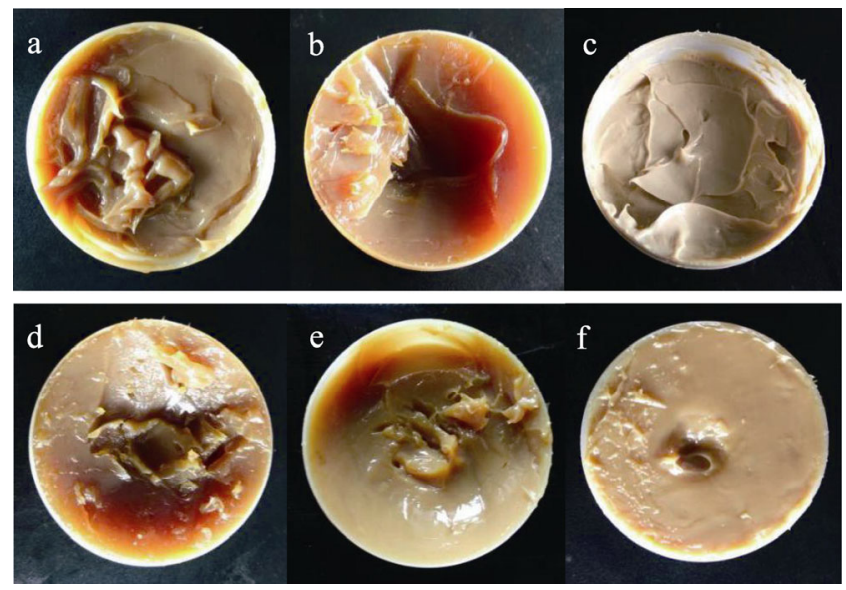

Fig. 1 Photos of as-prepared PUG via regulating organic amine: (a) Octadecylamine, (b) cyclohexylamine, (c) p-toluidine, (d) $\mathrm{O}+\mathrm{C}(1: 1)$, (e) $\mathrm{O}+\mathrm{P}(1: 1)$, and (f) $\mathrm{C}+\mathrm{P}(1: 1)$. 
national standards GB/T 7326-87 (ASTM D4048-81). The oil separation was tested by the national petrochemical industry standards SH/T 0324-92. Their functional groups were conducted by Fourier transform infrared analysis (FTIR, Nicolet-5700), and thermogravimetric analysis was performed by the NETZSCH SAT 449 F3 (NETZSCH Instrument Manufacturing Co., Ltd.).

\subsection{Salt spray test}

The salt spray test is an accelerated corrosion method that uses artificial salt spray [25]. Therefore, the corrosion rate is greatly accelerated by a factor of several times compared to natural environments. The neutral salt spray test was conducted in this experiment for 1 month following GB/T 1771-2007, whereby changes of the sample were observed at regular intervals. The temperature of the test chamber was $35{ }^{\circ} \mathrm{C}$ and the content of $\mathrm{NaCl}$ solution was $3.5 \%$. The grease was uniformly coated on the surface of low-carbon steel (Q235 (GB/T 700-2006)) with a thickness of $2 \mathrm{~mm}$. The grease-free sample was utilized as a reference. After the salt spray test, the grease on the low-carbon steel was cleaned up with a scraper and the low-carbon steel sheets were ultrasonically cleaned several times in alcohol. The surface topographies and elemental composition before and after tests were investigated to verify the anti-corrosion property using a JMS-6610 scanning electron microscope (SEM, JEOL, Japan) with energy disperse spectroscopy (EDS).

\subsection{Tribological properties of as-prepared PUG}

The Universal Mechanical Tester (UMT)-3 reciprocating friction and wear tribometer (Center For Tribology Company, USA) with ball-on-plate contact was employed to investigate the tribological performance under low load conditions. The commercially available lower steel disk (AISI 52100 steel, $\Phi 24 \mathrm{~mm} \times 7.9 \mathrm{~mm}$, the surface roughness $R a=80 \mathrm{~nm}$ ) slides against the upper ball (commercially available AISI 52100 steel, diameter of $9.52 \mathrm{~mm}$, the surface roughness $R a=$ $50 \mathrm{~nm}$ ). The UMT-3 tribometer was linked to a computer to record the real-time coefficient of friction. Ultrasonic cleaning was used for cleaning the friction pairs completely before characterization. All the tests were conducted at a reciprocating stroke of $5 \mathrm{~mm}$, frequency of $2 \mathrm{~Hz}$, test period of $1 \mathrm{~h}$, and applied load of $10 \mathrm{~N}$ (Hertzian contact pressure (HCP, $1 \mathrm{GPa})$ ) and $60 \mathrm{~N}$ (HCP, $1.82 \mathrm{GPa})$, respectively. All experiments were conducted under the same working conditions three times to ensure repeatability. Before the friction tests, approximately $1 \mathrm{~g}$ of grease was introduced to the ball-disk contact area with the fully flood lubrication conditions. The high load friction test was evaluated by the optimal SRV-V reciprocation friction tester (optimal, German) at room temperature and high temperature $\left(120{ }^{\circ} \mathrm{C}\right)$ with a ball-on-disk configuration. The same kinds of steel ball and the steel disk as the low load were used to slide against each other with an applied load of $250 \mathrm{~N}$, stroke length of $1 \mathrm{~mm}$, and frequency of $25 \mathrm{~Hz}$. The wear loss of the lower disk was determined by the Bruker Contour GT White-light interferometer. The wear loss of the lower disk was measured as follows: First, the two dimensional (2D) morphology of the wear scar (namely the wear depth and width) was measured using a white-light interferometer. Second, the cross-sectional area of the wear track was calculated by the software origin. Finally, the wear loss was obtained by multiplying the cross- sectional area with the length of wear scar. The measurement was repeated at least three times to reduce errors and ensure accuracy. The optimal SRV-V reciprocation friction tester was employed to evaluate the extreme pressure property with a frequency of $25 \mathrm{~Hz}$, a stroke length of $1 \mathrm{~mm}$, and a step load of $50 \mathrm{~N} / 3 \mathrm{~min}$ at room temperature.

For further investigation of the tribological performance, the four-ball experiments (Yihua, Jinan) were carried out with a load of $392 \mathrm{~N}$, a rotational speed of $600 \mathrm{r} / \mathrm{min}$, and $120 \mathrm{~min}$ at room temperature. Before each experiment, the balls and the oil cup were cleaned by petroleum ether for $15 \mathrm{~min}$ through ultrasonication. The coefficients of friction were automatically recorded on a computer linked to the four-ball machine. The wear scar diameter (WSD) of the lower three stationary steel balls was measured by an optical microscope. The average values of WSD were calculated by measuring the WSD of the lower three stationary steel balls. Chinese National Standard GB3142, similar to ASTM D-2783, was adopted for 
the tests.

\subsection{Worn surface analysis}

To explore the friction mechanism under PUG lubrication, the morphology of worn surfaces was observed by JSM-6610LV SEM (JEOL, Japan) and the white-light interferometer. The elemental composition and chemical states on the worn surfaces were analyzed by Thermo Scientific ESCALAB 250Xi X-ray photoelectron spectroscopy (XPS).

\section{Results}

\subsection{Physical properties of as-prepared PUG}

Table 1 presents the physicochemical properties of the as-prepared PUGs. The dropping points of asprepared grease are exceedingly high (over $200{ }^{\circ} \mathrm{C}$ ). Except for the PUG prepared by octadecylamine, the other PUGs possess a higher dropping point of over $260{ }^{\circ} \mathrm{C}$. The PUG (C+P (2:1)) shows the highest dropping point, reaching up to $305^{\circ} \mathrm{C}$. The penetration parameters exhibit the better thickening capacity of as-prepared PUGs. The O+C (1:1) shows the best thickening capacity, allowing the National Lubricating Grease Institute (NLGI) grade to 6. For the copper corrosion test, the copper exhibits nearly no change compared with the polished copper, allowing the degree at $1 \mathrm{a}$, whereas the coated-free copper strips appeared severely corroded, indicating the excellent corrosion resistance of as- prepared grease. The oil separation test revealed lower percentages of oil separation (less than $10 \mathrm{wt} \%$ ), indicating excellent colloid stability of as-prepared PUGs. From the above discussion, the PUG formulated by $\mathrm{C}+\mathrm{P}(2: 1)$ possesses the best physicochemical properties. The variation of physicochemical properties resulted from the physical interaction of thickener material and base oil (such as van der Waals forces and capillary forces).

To investigate the thermal stability of as-prepared greases, the PUGs (onefold amine, 1:1 ratio) were selected to measure the thermogravimetric analysis (TGA) and differential thermal gravity (DTG). Figure 2 shows the TGA and DTG curves of as-selected PUG. The temperature was increased gradually
Table 1 Physicochemical properties of PUG with different organic amines.

\begin{tabular}{|c|c|c|c|c|c|c|}
\hline \multicolumn{2}{|c|}{$\begin{array}{c}\text { Organic amines } \\
\text { property }\end{array}$} & $\begin{array}{l}\text { Dropping } \\
\text { point }\left({ }^{\circ} \mathrm{C}\right)\end{array}$ & \multicolumn{2}{|c|}{$\begin{array}{l}\text { Penetration } \\
(0.1 \mathrm{~mm}) \\
\text { NLGI grade }\end{array}$} & $\begin{array}{c}\text { Copper } \\
\text { corrosion } \\
\left(100^{\circ} \mathrm{C}, 24 \mathrm{~h}\right)\end{array}$ & $\begin{array}{c}\text { Oil } \\
\text { separation } \\
(\%)\end{array}$ \\
\hline \multicolumn{2}{|c|}{$\begin{array}{l}\text { National } \\
\text { standard }\end{array}$} & $\begin{array}{l}\text { ASTM- } \\
\text { D566 }\end{array}$ & \multicolumn{2}{|c|}{$\begin{array}{c}\text { ASTM-D21 } \\
7\end{array}$} & $\begin{array}{c}\text { ASTM- } \\
\text { D4048-81 }\end{array}$ & $\begin{array}{c}\mathrm{SH} / \mathrm{T} \\
0324-92\end{array}$ \\
\hline \multicolumn{2}{|c|}{ Octadecylamine } & 200 & 234 & 3 & $1 \mathrm{a}$ & 8.0 \\
\hline \multicolumn{2}{|c|}{ Cyclohexylamine } & 289 & 177 & 4 & $1 \mathrm{a}$ & 2.5 \\
\hline \multicolumn{2}{|c|}{ P-toluidine } & 263 & 215 & 3 & $1 \mathrm{a}$ & 6.0 \\
\hline \multirow{3}{*}{$\mathrm{O}+\mathrm{C}$} & $1: 2$ & 275 & 142 & 5 & $1 \mathrm{a}$ & 3.2 \\
\hline & $2: 1$ & 279 & 151 & 5 & $1 \mathrm{a}$ & 3.8 \\
\hline & $1: 1$ & 278 & 121 & 6 & $1 \mathrm{a}$ & 3.5 \\
\hline \multirow{3}{*}{$\mathrm{O}+\mathrm{P}$} & $1: 2$ & 304 & 202 & 4 & $1 \mathrm{a}$ & 4.5 \\
\hline & $2: 1$ & 279 & 214 & 3 & $1 \mathrm{a}$ & 3.2 \\
\hline & $1: 1$ & 312 & 226 & 3 & $1 \mathrm{a}$ & 3.8 \\
\hline \multirow{3}{*}{$\mathrm{C}+\mathrm{P}$} & $1: 2$ & 283 & 232 & 3 & $1 \mathrm{a}$ & 5.6 \\
\hline & $2: 1$ & 305 & 246 & 3 & $1 \mathrm{a}$ & 1.7 \\
\hline & $1: 1$ & 300 & 243 & 3 & $1 \mathrm{a}$ & 2.3 \\
\hline
\end{tabular}

from ambient temperature to $600{ }^{\circ} \mathrm{C}$ at a heating rate of $10^{\circ} \mathrm{C} \cdot \mathrm{min}^{-1}$ in nitrogen. The start decomposition temperature and the fastest decomposition temperature are indicated in Fig. 2. From Fig. 2, we draw the following conclusions: as-synthesized grease has excellent thermal stability; the start decomposition temperatures are in the range of $275-318{ }^{\circ} \mathrm{C}$ (Figs. 2(a) and 2(b)); the formulation of cyclohexylamine reaches the highest decomposition temperature, and the decomposition rate is approximately the same. The changes in the functional groups of PUGs were analyzed by FTIR (Fig. 3). The deformation vibration of the $\mathrm{N}-\mathrm{H}$ bond appeared at $3303 \mathrm{~cm}^{-1}$. The peak located at $1,315 \mathrm{~cm}^{-1}$ belongs to the stretching vibration peak of the $\mathrm{C}-\mathrm{N}$ bond. The stretching vibration peak of the $\mathrm{C}=\mathrm{O}$ bond appeared at $1,630 \mathrm{~cm}^{-1}$. The appearance of these bonds clearly demonstrated the existence of the carbamido in the polyurea thickener [12, 13, 23].

\subsection{Surface analysis of the salt spray test}

The SEM was employed to observe the surface morphologies of low-carbon steel. The morphologies of low-carbon steel and the corresponding EDS analysis were displayed in Fig. 4. The surfaces of grease-coated steel were smooth and flat, which were nearly unchanged from the polished steel ones. In contrast, the coated-free surface was severely 

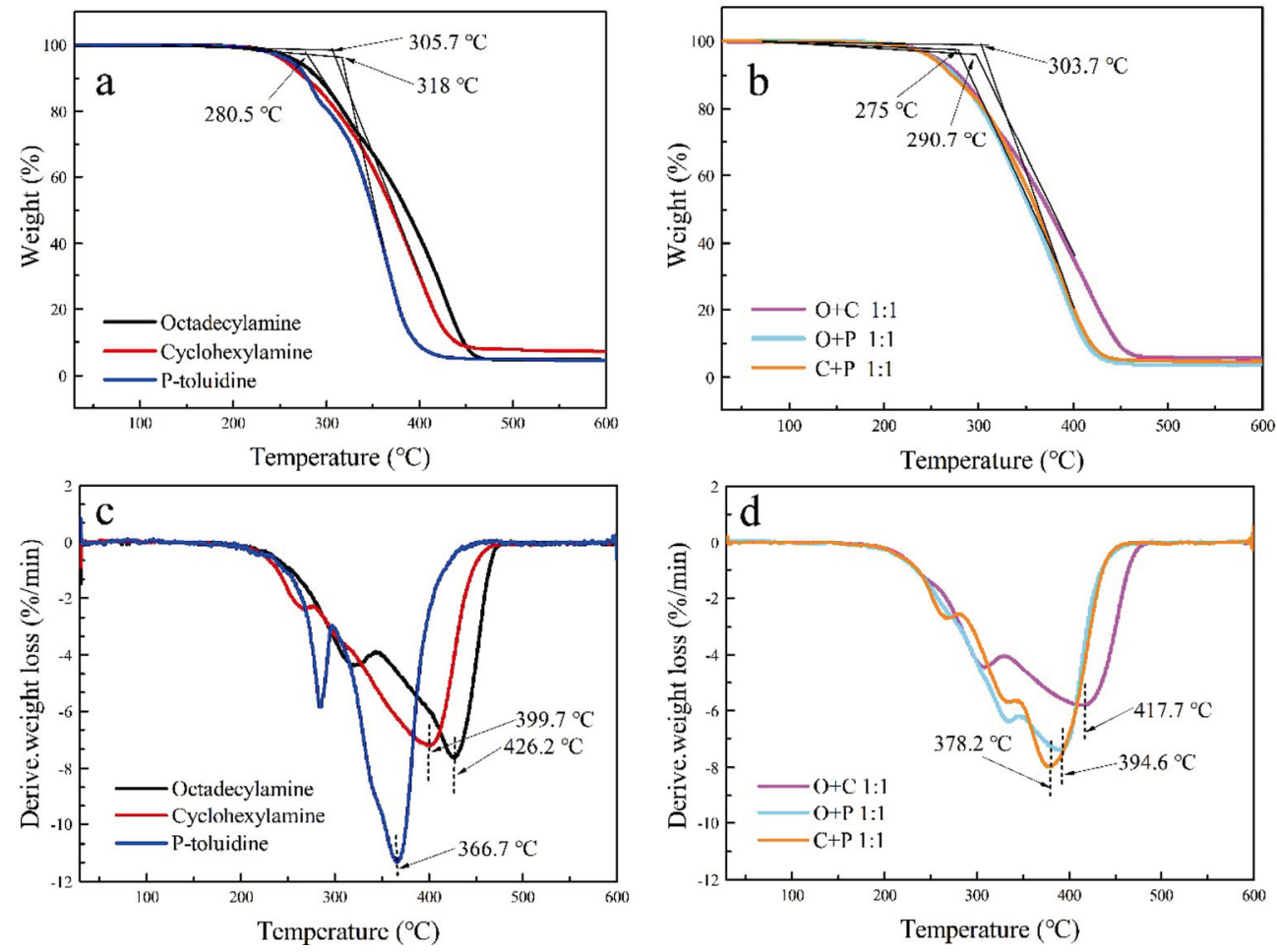

Fig. 2 (a, b) TGA and (c, d) DTG curves of as-selected PUG.
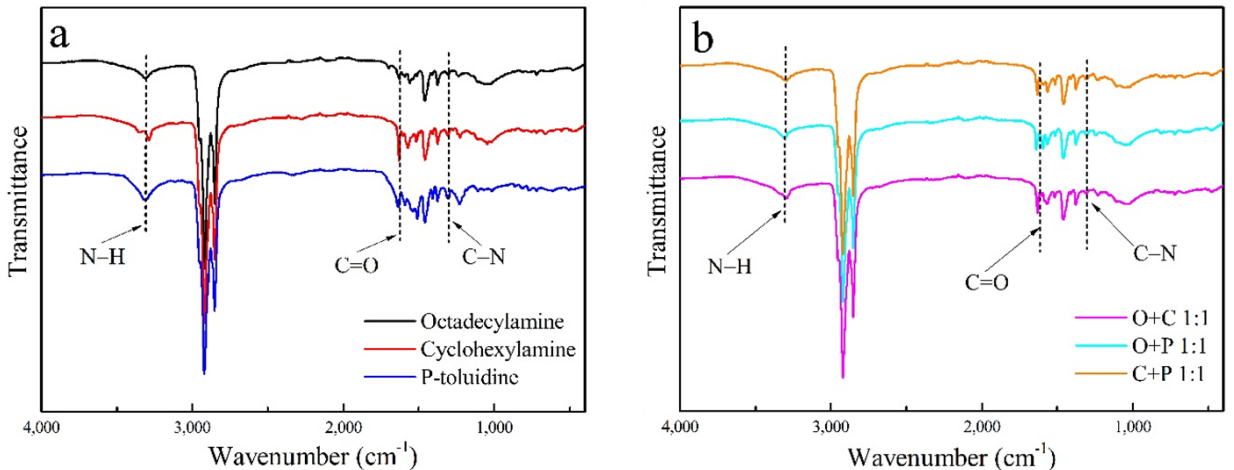

Fig. 3 FTIR spectra of as-selected PUG before the salt spray test.

corroded and covered with corroded products. The EDS results indicate that the elements $\mathrm{C}, \mathrm{Fe}$, and $\mathrm{Mn}$ appear on all surfaces, as the inherent elements in the low-carbon steel. However, the coating-free surface had other elements of $\mathrm{Cl}$ and $\mathrm{O}$, suggesting that oxidation occurred on the lowcarbon steel, and $\mathrm{Cl}^{-}$reacted with the elements on the surface. The contents of $\mathrm{Cl}$ and $\mathrm{O}$ elements are displayed in Table 2. The grease-free samples appear high content of $\mathrm{O}$ elements and a small amount of $\mathrm{Cl}$ elements, whereas the grease-coated sample had none. The EDS results are in good agreement with the surface features, which strongly verify the corrosion resistance of as-prepared PUGs. The excellent physicochemical performance of as-prepared grease plays a significant role in the corrosion resistance. The high dropping point allows the greases to keep the original structure when operating at high temperatures. The good thickening ability allows the greases to possess good adhesiveness, which contributes to the good sealing function. The oil separation reflects the outstanding colloid stability of greases, namely the poor oil-releasing ability under high temperatures or pressures. The PUGs prepared by different organic amines have excellent physicochemical performance, contributing 

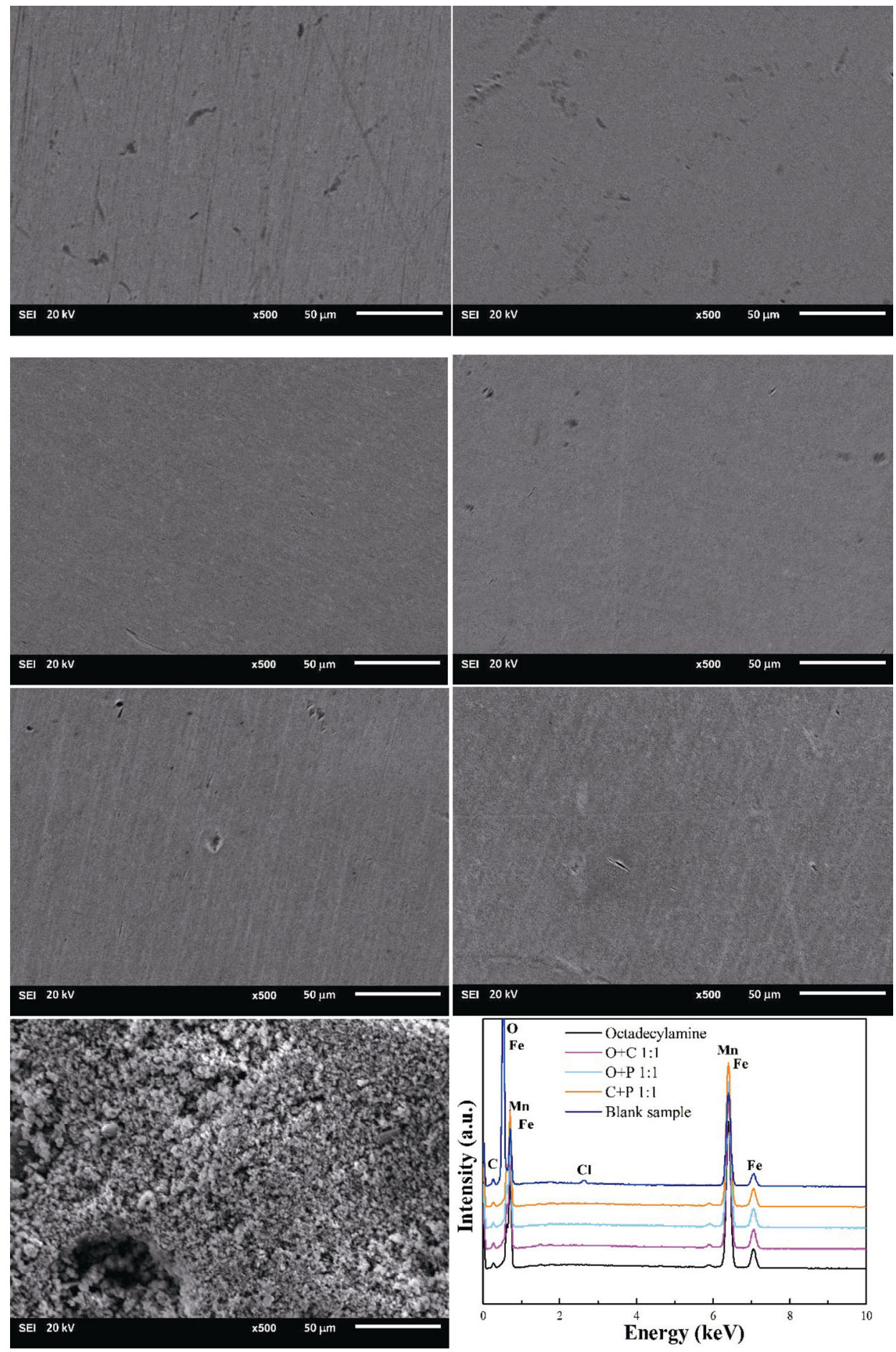

Fig. 4 SEM morphologies of low-carbon steel after salt spray test and the corresponding EDS on the surface of low-carbon steels.

to the improvement of adaptability in harsh environments.

\subsection{Tribological performance of as-prepared PUG}

The friction coefficients and relevant wear volumes performed by UMT-3 reciprocating friction and wear tribometer are shown in Figs. 5-7. The friction coefficients of all PUGs are in the range of 0.08-0.1. The formulations of $\mathrm{O}+\mathrm{P}(1: 1)$ and $\mathrm{C}+\mathrm{P}(1: 2)$ provided the lowest friction coefficient at 60 and 
Table 2 Contents of $\mathrm{Cl}$ and $\mathrm{O}$ on the coating-free and grease coated surface.

\begin{tabular}{cccccc}
\hline \multirow{2}{*}{ Project } & \multicolumn{2}{c}{$\mathrm{Cl}$} & & \multicolumn{2}{c}{$\mathrm{O}$} \\
\cline { 2 - 3 } \cline { 5 - 6 } & $\mathrm{wt} \%$ & $\mathrm{at} \%$ & & $\mathrm{wt} \%$ & $\mathrm{at} \%$ \\
\hline $\begin{array}{c}\text { Grease-free } \\
\text { samples }\end{array}$ & 0.46 & 0.37 & & 34.06 & 61.04 \\
$\begin{array}{c}\text { Grease-coated } \\
\text { samples }\end{array}$ & 0 & 0 & 0 & 0 \\
\hline
\end{tabular}

$10 \mathrm{~N}$, respectively. The formulations of $\mathrm{C}+\mathrm{P}(1: 1$ and 1:2) exhibited the minimum wear volume at 60 and $10 \mathrm{~N}$, respectively, indicating that the two formulations have the best anti-wear ability. The wear volumes of $\mathrm{C}+\mathrm{P}$ are lower than of the other formulation, indicating that the combination of cyclohexylamine and p-toluidine can improve the wear resistance of PUG.

The friction coefficients carried out by four-ball tester are displayed in Fig. 8. The average friction coefficients are in the range of $0.09-0.13$. The $\mathrm{C}+\mathrm{P}$ (1:2) provided the lowest friction coefficient (0.095), suggesting better friction-reducing ability. Figure 9 shows the relevant WSD of the four-ball test. The PUG prepared by the combination of cyclohexylamine and p-toluidine presents shorter WSD than the other formulation of grease, indicating that the PUG is formulated by the combination of cyclohexylamine and p-toluidine has a better anti-wear capacity. Among the formulation of $\mathrm{C}+\mathrm{P}$ in three different ratios, the $\mathrm{C}+\mathrm{P}(1: 2)$ reveals the shortest WSD (0.41), which is in good agreement with the results of the friction coefficient. Simply, the formulation of $\mathrm{C}+\mathrm{P}(1: 2)$ has the best friction-reducing and anti-wear ability at high load conditions.

The PUGs formulated by onefold organic amine and the combination of cyclohexylamine and p-toluidine in three ratios were selected to evaluate the extreme pressure, as shown in Fig. 10. The PUG formulated by $\mathrm{C}+\mathrm{P} \quad(2: 1)$ demonstrates the best load-carrying capacity, reaching up to $800 \mathrm{~N}$, followed by the formulation of cyclohexylamine $(700 \mathrm{~N})$. The PUG prepared by p-toluidine has the lowest load-carrying capacity. The load-carrying capacity from high to low is in the following order: $\mathrm{C}+\mathrm{P}(2: 1)>\mathrm{C}+\mathrm{P}(1: 2)>$ p-toluidine $>\mathrm{C}+\mathrm{P}(1: 1)>$ octadecylamine $>$ cyclohexylamine. The majority of PUG provided excellent extreme pressure property, which could bear the high load in extreme pressure conditions.

The PUGs prepared by cyclohexylamine, and the combination of cyclohexylamine and p-toluidine in three ratios were selected to evaluate the tribological performance of steel/steel contact under high loads. The relevant friction coefficients and wear volumes

were displayed in Fig. 10. The PUG prepared by $\mathrm{C}+\mathrm{P}(1: 1)$ has the lowest friction coefficient and a low wear volume, indicating that the formulation of $\mathrm{C}+\mathrm{P}(1: 1)$ presents the best lubrication function, which is in agreement with the results of WSD. Figure 10(d) shows the friction behavior and corresponding wear volume lubricated by the formulation of cyclohexylamine and $\mathrm{C}+\mathrm{P}(1: 2)$ at $120{ }^{\circ} \mathrm{C}$ with an applied load of $300 \mathrm{~N}$. The friction coefficient and the relevant wear volume are higher than those at room temperature. The $\mathrm{C}+\mathrm{P}(1: 2)$ still demonstrates a good lubrication function.

\subsection{Morphology analysis of worn surface}

Some representative morphologies of wear scar carried out by the four-ball tester and corresponding EDS results are displayed in Fig. 11, which are in agreement with the average WSD showed in Fig. 9. Obvious furrows can be clearly observed on the surface of the wear scar, indicating abrasive wear is dominant. The formulation of $\mathrm{p}$-toluidine presents the largest wear scar, whereas $\mathrm{C}+\mathrm{P}(1: 1)$ shows the smallest wear scar. The surface of wear scar lubricated by octadecylamine and cyclohexylamine shows some abrasive dust. The EDS was employed to analyze the elementary composition of the worn surface and the abrasive dust. The $\mathrm{O}$ content of the abrasive dust was higher than that on the surface of the wear scar (Figs. 11(e) and 11(f)), indicating oxidative wear appeared on the worn surface. The wear scar lubricated by the formulation of $\mathrm{O}+\mathrm{P}(1: 1)$ had a slight oxidation wear on the worn surface.

\subsection{XPS analysis of worn surface}

XPS was employed for a better understanding of the lubrication mechanisms. Figure 12 shows the XPS spectra of typical elements under the steel/ steel contact. The C 1s peak appears at $284.8 \mathrm{eV}$, which is attributed to the carbon in the atmosphere. The $\mathrm{O}$ spectrum has two peaks located at 529.8 

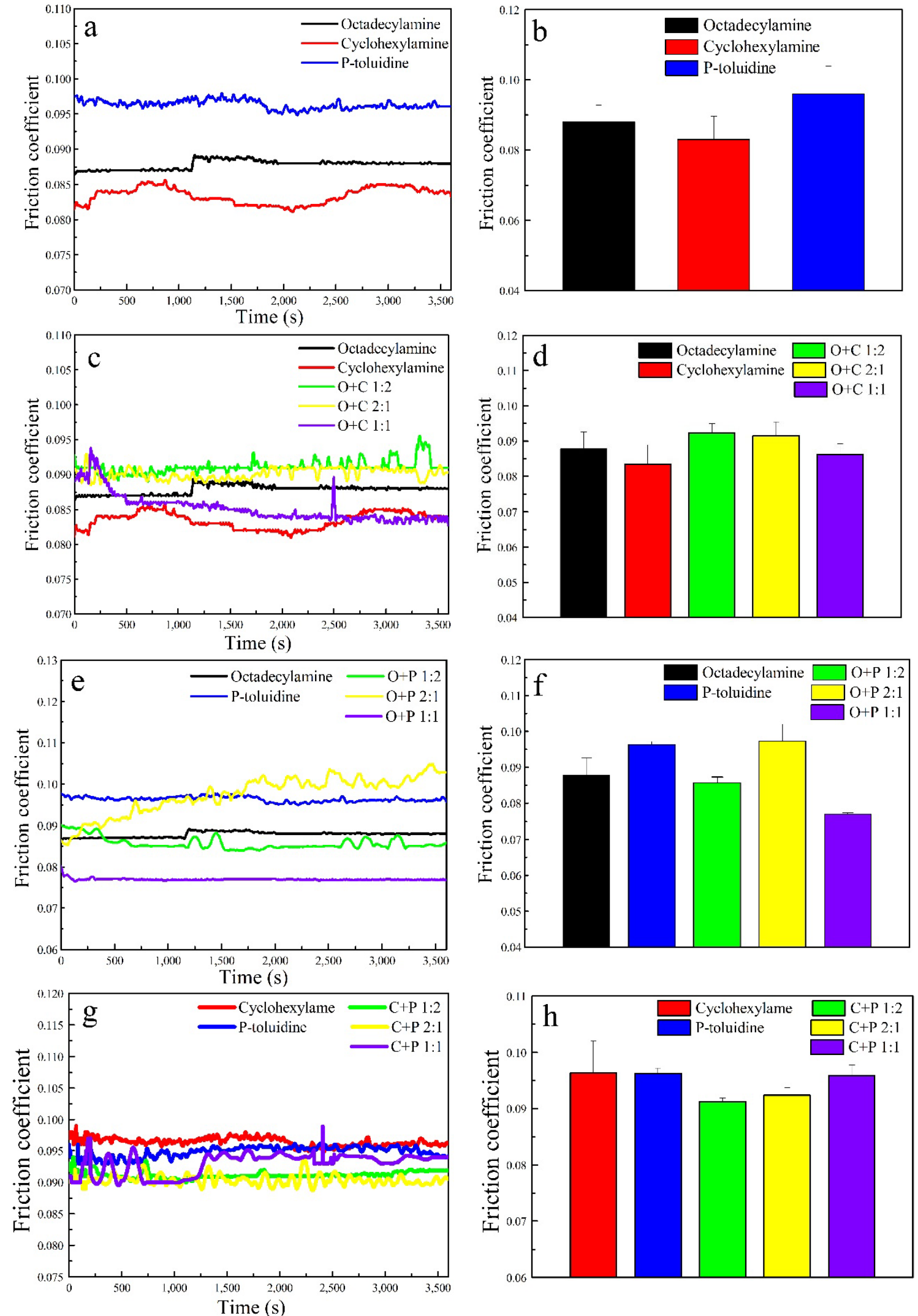

Fig. 5 Friction coefficients of PUG conducted by the reciprocating friction and wear tribometer at $60 \mathrm{~N}$. 

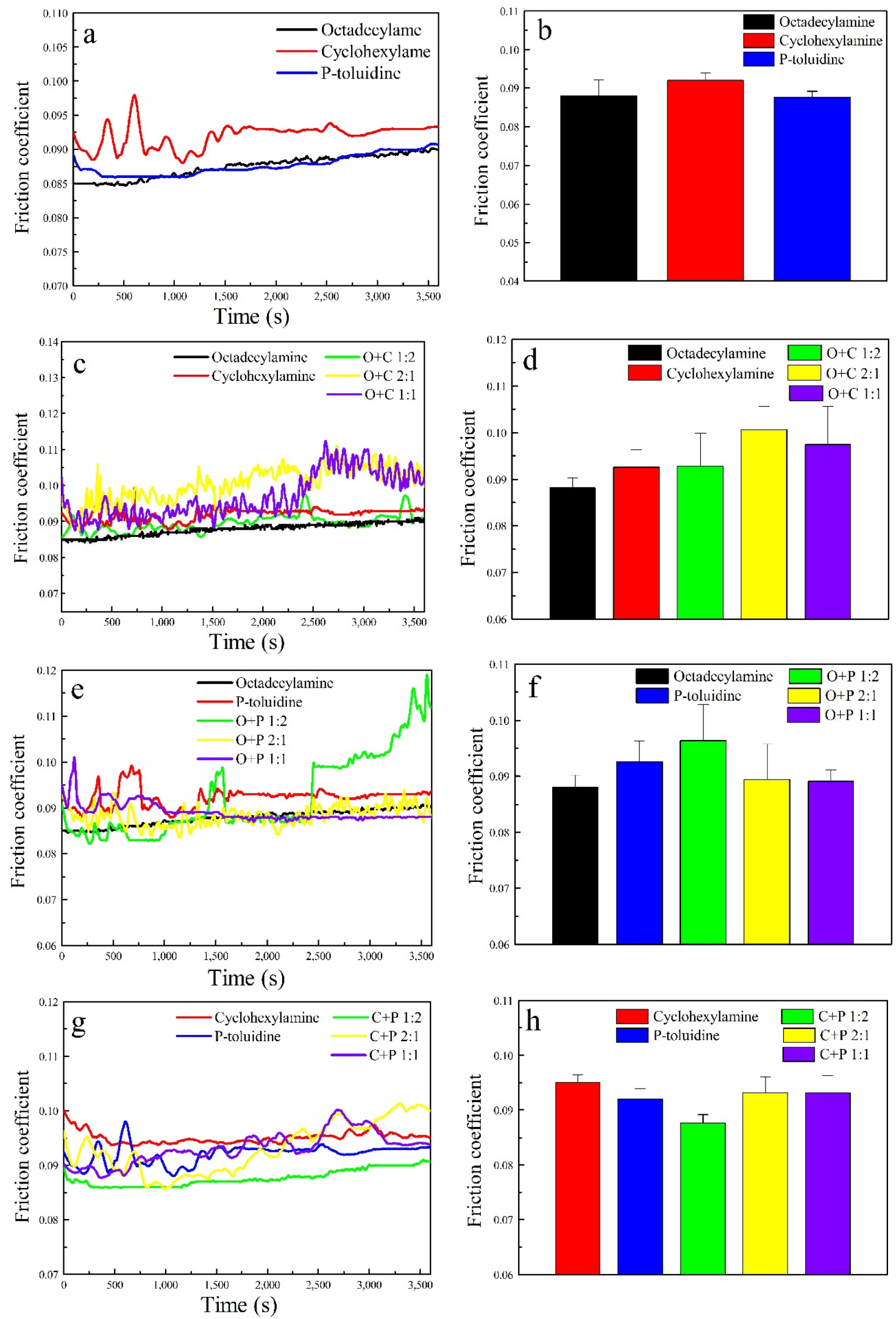

Fig. 6 Friction coefficients of PUG conducted by the reciprocating friction and wear tribometer at $10 \mathrm{~N}$. 

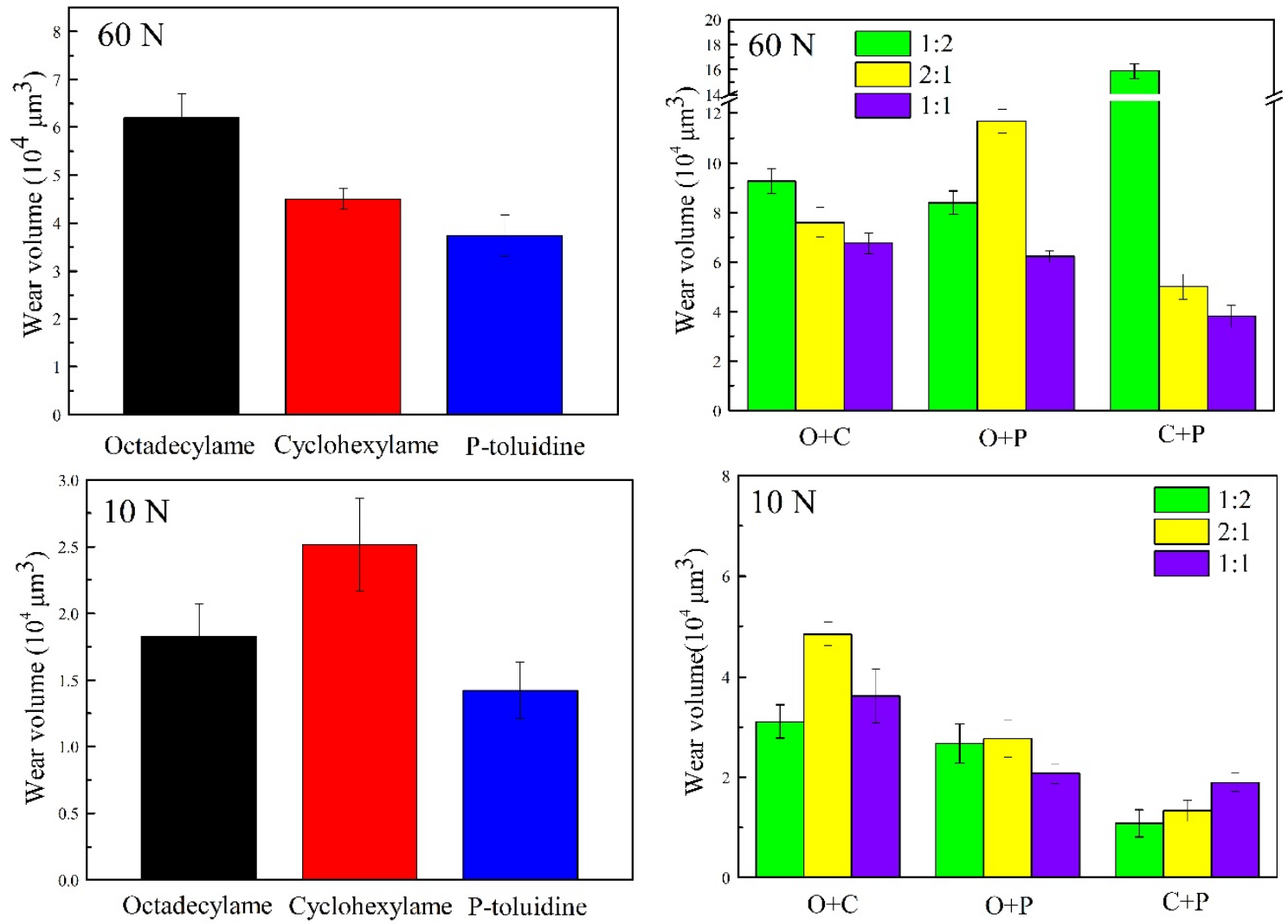

Fig. 7 Evolution of wear volume on the steel plates lubricated with as-prepared PUG at different applied loads (60 and $10 \mathrm{~N})$.

and $532.3 \mathrm{eV}$, possibly due to the appearance of the iron oxide [25]. The spectra of Fe have three peaks located at 706.0, 709.8, and $723.8 \mathrm{eV}$, respectively, further indicating the formation of $\mathrm{Fe}_{2} \mathrm{O}_{3}, \mathrm{FeOOH}$ [26]. The $\mathrm{N} 1$ s peak located at $400.2 \mathrm{eV}$, corresponding to the $\mathrm{C}-\mathrm{N}$ bonding and nitrogen transformation to amine or nitrogen oxide, possibly attributed to the deposited film composed of thickener and the products of tribo-chemical reaction [27]. XPS analysis supports the formation of a tribo-chemical reaction film formed on the worn surface, including $\mathrm{Fe}_{2} \mathrm{O}_{3}$, $\mathrm{FeOOH}$, and nitrides [28, 29]. The generated friction heat from the relatively moving friction pairs promoted the appearance of the oxide layer $\left(\mathrm{Fe}_{2} \mathrm{O}_{3}, \mathrm{FeOOH}\right)$. The characteristic of an oxide layer is considered a significant element for wear resistance in the boundary lubrication conditions. The $\mathrm{FeOOH}$ is characterized by the dense and durable structure, whereas the $\mathrm{Fe}_{2} \mathrm{O}_{3}$ is likely to strip because of its loose structure. The content of $\mathrm{FeOOH}$ is higher than $\mathrm{Fe}_{2} \mathrm{O}_{3}$, making the friction surface less easily stripped off [28]. Thus, $\mathrm{FeOOH}$ and $\mathrm{Fe}_{2} \mathrm{O}_{3}$ formed dense and tough oxide layers, contributing to the anti-wear property. The oxide layer was continually ground off in the process of friction, which was then replaced by the newly generated film. The oxide layer has poor anti-shear ability, preventing abrasive wear in the friction interface. Therefore, the tribo-chemical reaction film improves friction reduction and anti-wear performance on the interface.

\section{Discussion}

\subsection{Effect of thickener component on lubrication process}

Due to the two phases of a grease system, the process and mechanism of friction are quite complex. PUGs prepared by different organic amine processes have different consistencies (mobilities). As the friction test continues, most of the grease is pushed outside of the contact area, and only a small amount of grease is involved in the lubrication [30]. The thickener 

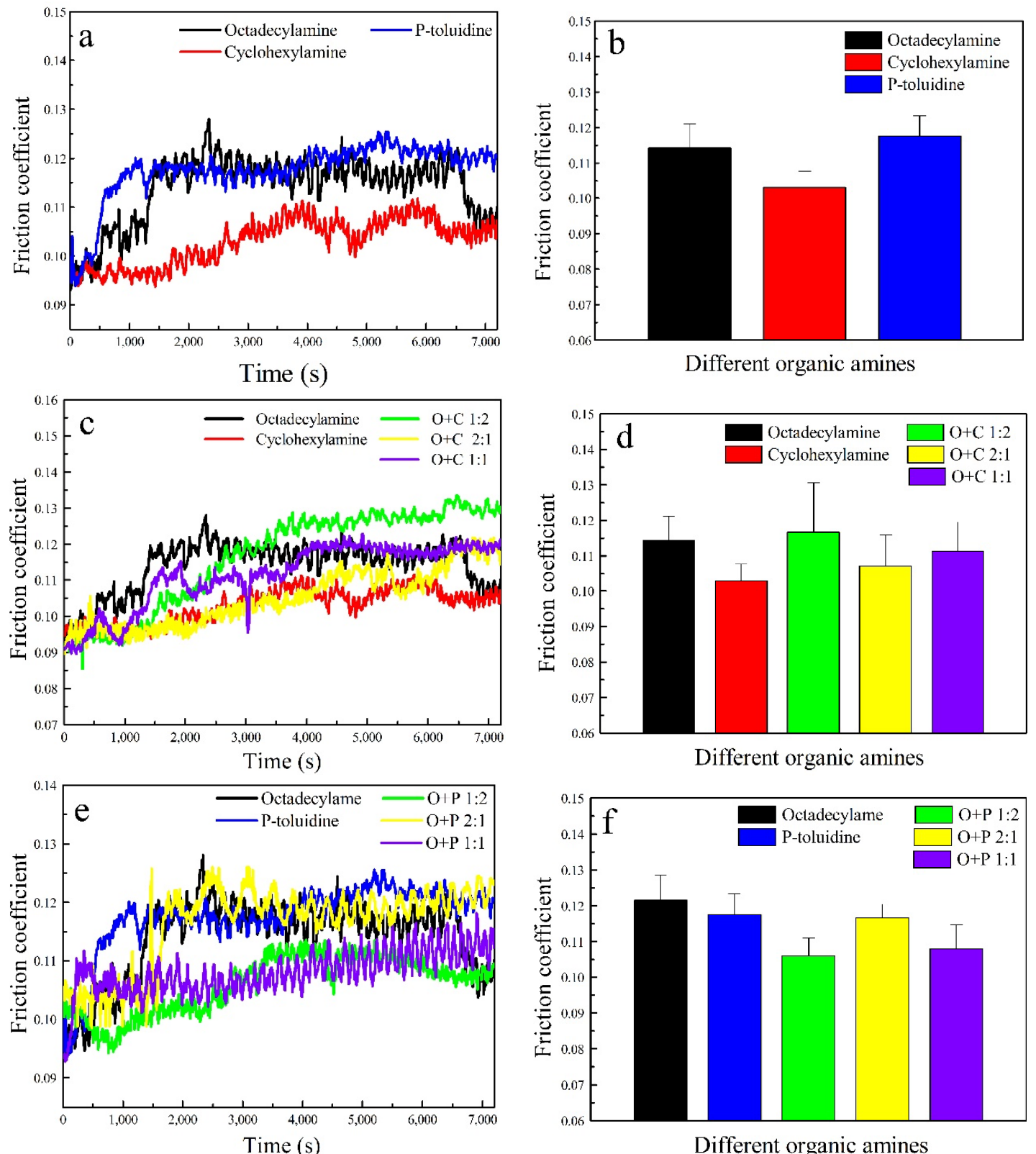

Different organic amines

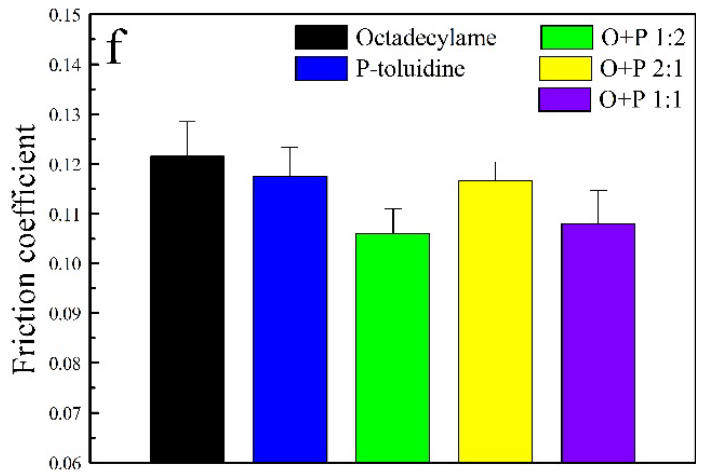

Different organic amines
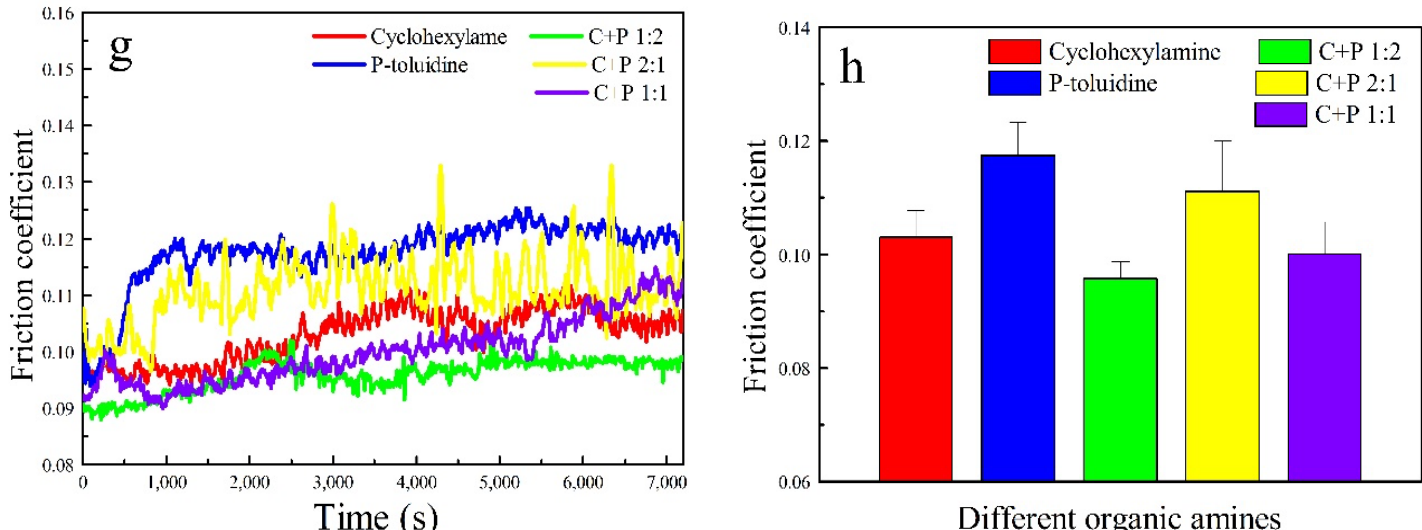

Different organic amines

Fig. 8 Variation of friction coefficients lubricated by as-prepared PUG on four-ball tester at an applied load of $392 \mathrm{~N}$ and rotation speed of $600 \mathrm{r} / \mathrm{min}$ for $2 \mathrm{~h}$. 

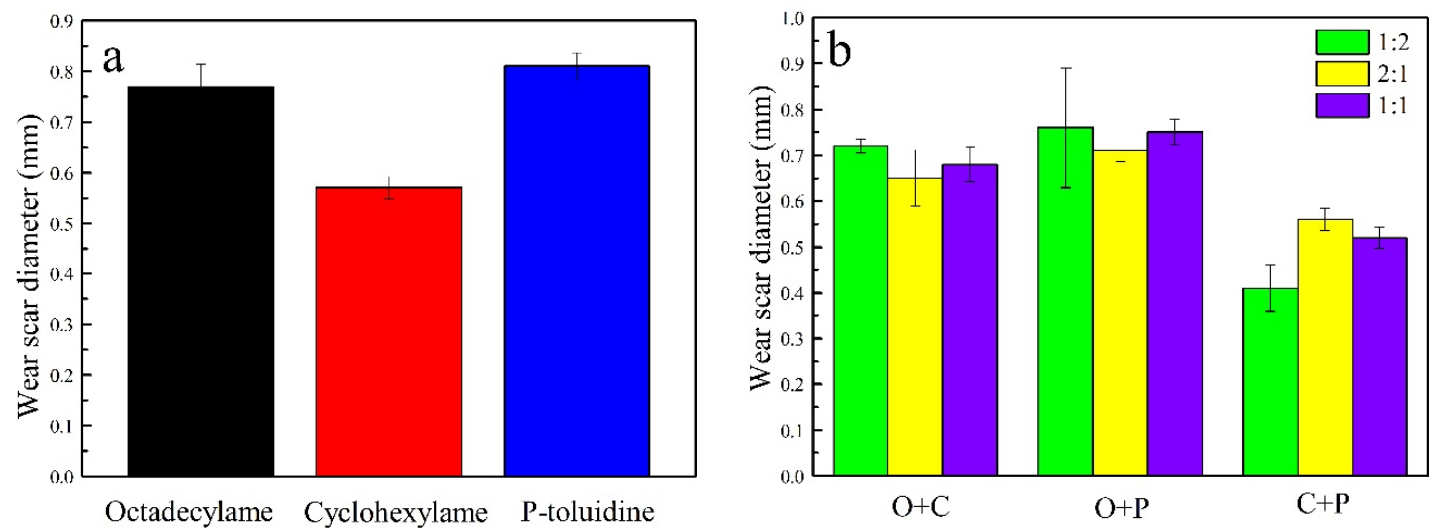

Fig. 9 Variation of WSD lubricated by as-prepared PUG.
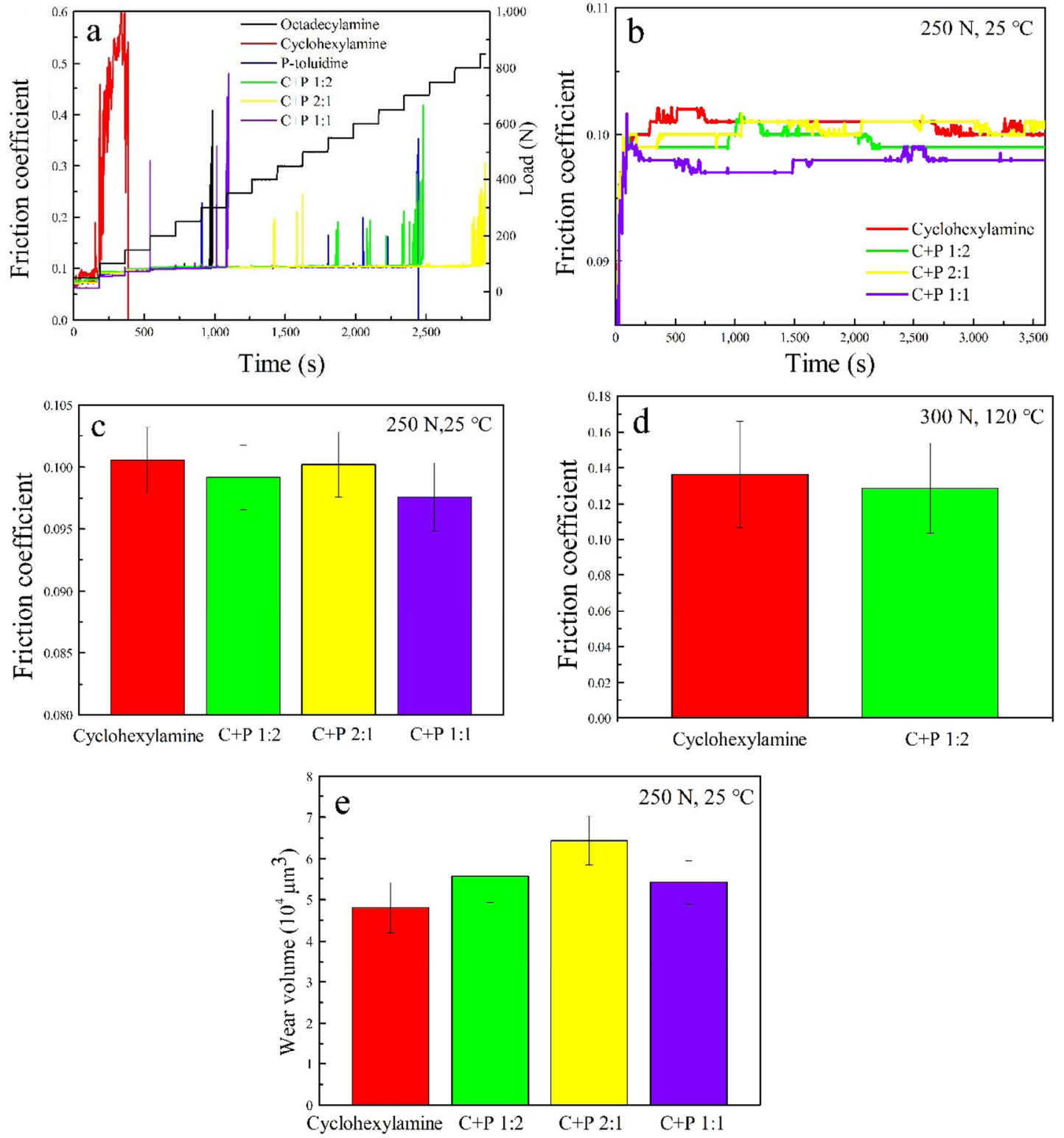

Fig. 10 (a) Extreme pressure property of as-selected grease, (b, c) friction coefficients, and (d, e) corresponding wear volumes lubricated by as-selected PUG on optimal SRV-V reciprocation friction tester at 25 and $120{ }^{\circ} \mathrm{C}$. 

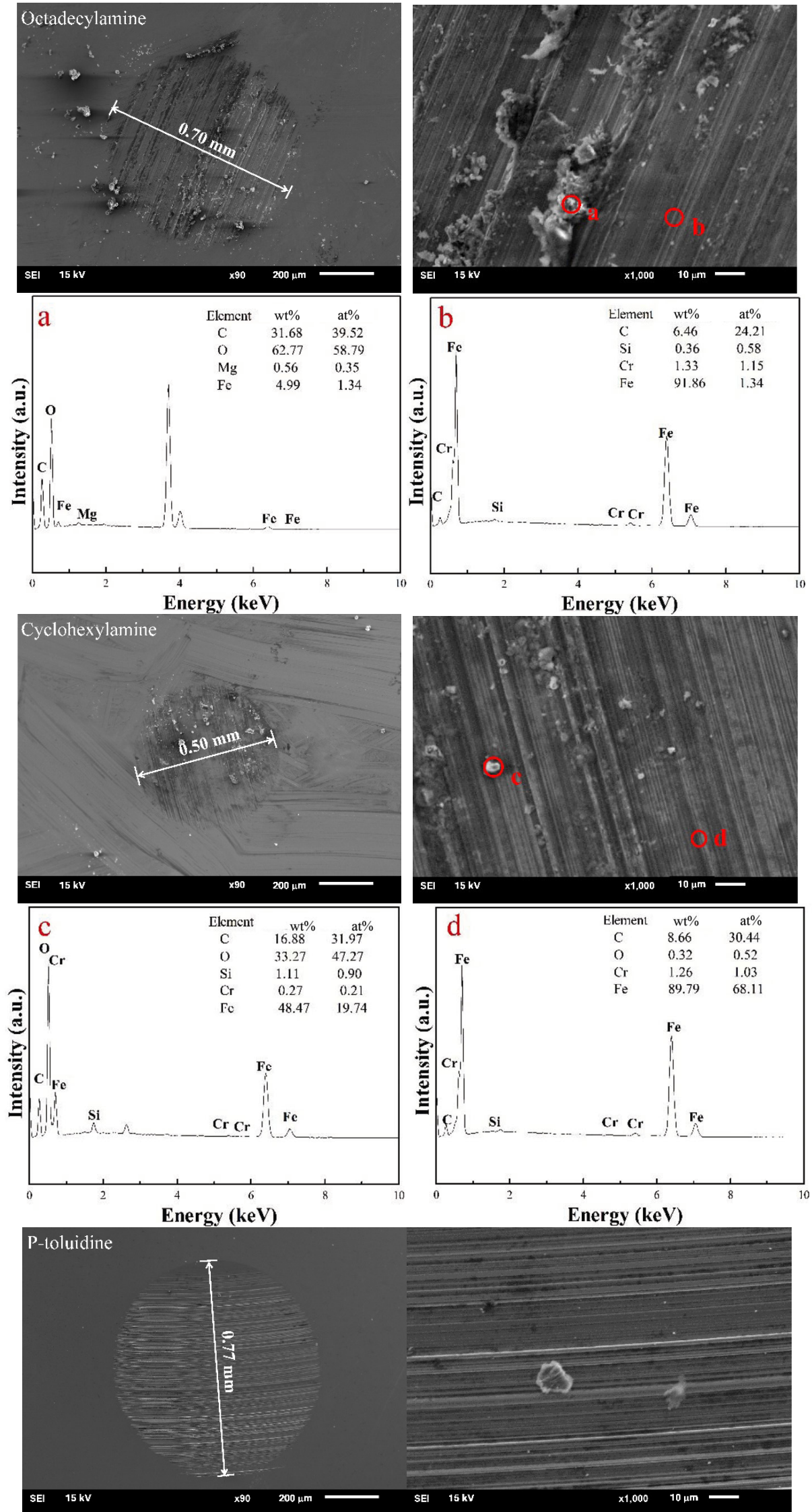

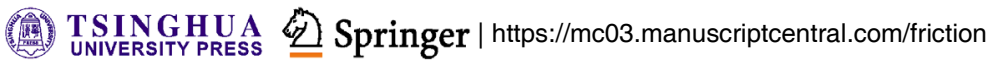



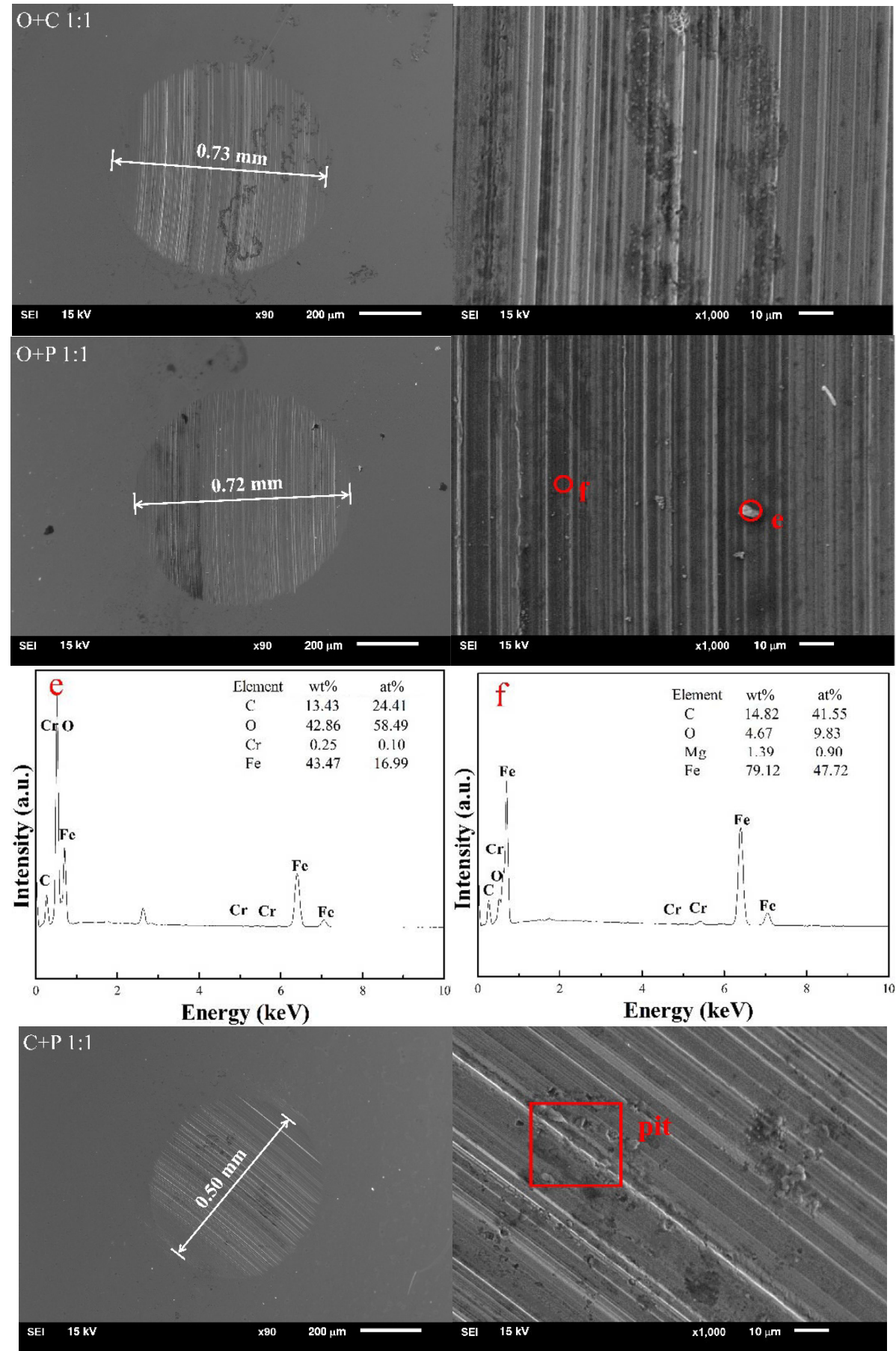

Fig. 11 SEM images of wear scar carried out by four-ball tester and corresponding EDS analysis.

structure on the contact area is destroyed by the shear stress released by the base oil from the thickener structure [31]. Simply, the thickener acts as an oil reservoir releasing the base oil to the contact area [32]. Meanwhile, the contact area forms a hydrodynamic film with the effect of relative sliding of the friction pairs. The thickener particles are easily absorbed on the worn surface, which forms a surface layer with a higher viscosity [33]. Closed to the surface layer, the boundary layer forms superior flow properties because of containing fewer thickeners. Therefore, the wall effect is significant for the formation of oil film [34]. The lone pair of nitrogen atoms in the thickener allows 

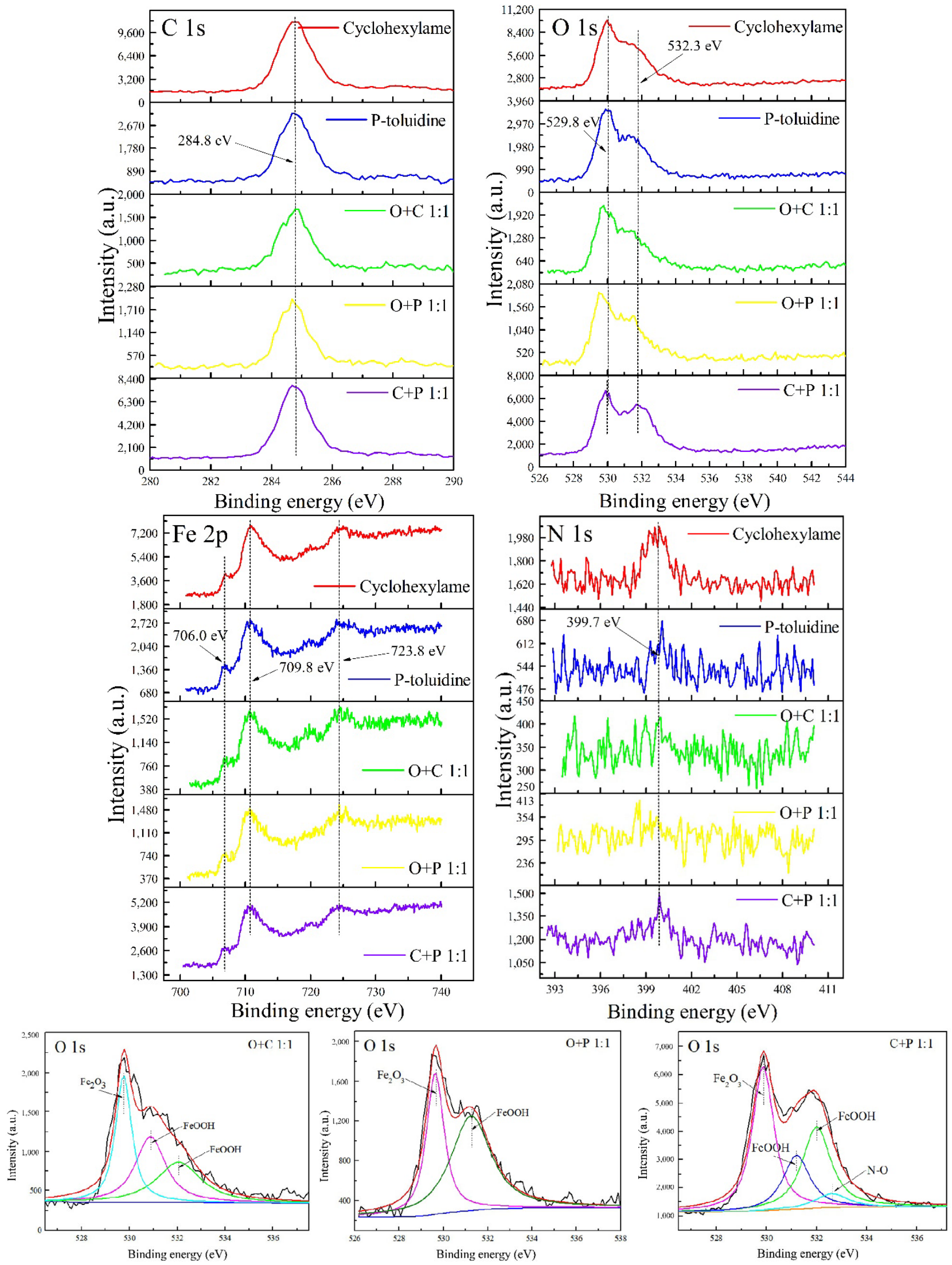

Fig. 12 X-ray photoelectron spectra of the elements on the worn surface lubricated with as-prepared PUG. 
the thickener to be easily absorbed on the worn surface for enhancing grease adhesion, and promoting the appearance of a tribo-chemical reaction film [6]. The tribo-chemical reaction film was formed on the worn surface during the repeated sliding process, which enhanced the friction-reducing and anti-wear performance. When the oil film is subjected to high stress/temperature, it will break down accompanied by a decrease in film thickness and aggravation of wear. At this moment, the lubrication is at starved conditions, whereby the tribo-chemical reaction film and thickener deposited film play a dominant role [19]. Meanwhile, the severe wear leads to the increasing temperature, which causes the base oil to bleed from the thickener and increases the mobility of base oil. The increasing temperature accelerates the base oil return to the track and replenishes the contact area, thereby recovering the starved conditions [35]. The lubrication of PUGs with high consistency is continually changed from the full flood condition to the starved condition, namely the dynamic behavior of lubrication, while PUGs with better mobility is at the steady-state [36]. The thickener agent causes the wear resistance to be inconsistent with the friction reduction, and thus affecting the lubrication process. In summary, the synergy effect of oil film, thickenerdeposited film, and tribo-chemical reaction film plays a significant role in friction reduction and wear resistance [37, 38]. Figure 13 shows the schematic diagram of a tribological mechanism.

\subsection{Effect of friction parameters on tribological performance}

The ingredient regulation of PUG by using different organic amines has a significant influence on the consistency and rheological properties, which strongly determines the lubrication states. The replenishment rate of lubrication relies on the oil/thickener interaction and rheological properties, as well as on the thickenerdeposited film [30]. The thickener-deposited film increases the contact angle of oil, causing the capillary pressure to decrease. Therefore, the bled oil cannot be replenished in the contact area, resulting in the lubrication at the starved conditions. Moreover, the tribological performance could be affected by the working conditions (such as speed, temperature, load, and movement forms). Stress is a significant factor in the oil-releasing mechanism that affects the lubrication conditions. If the stress reaches the critical point, known as yield stress, the thickener structure begins to deform and the base oil bleeds from it [15]. The stress has a significant influence on the breaking down and "repairing" behavior of oil film [39]. For the UMT-3 reciprocating friction test, some curves of friction coefficient of grease appear to fluctuate over time, because the friction coefficient sharply increases with the transformation from fully flood condition to starved condition. The higher wear volume is attributed to the long period of starved conditions (such as the formulation of $\mathrm{C}+\mathrm{P}(1: 2)$ at $60 \mathrm{~N}, \mathrm{O}+\mathrm{C}(2: 1)$ at $10 \mathrm{~N})$. The grease with better mobility hardly appears on the starved conditions, thereby the friction coefficient curves are smooth and the wear volumes are lower. To investigate the effect of temperature on tribological performance, the PUG was tested by the SRV-V reciprocation friction test at 25 and $120{ }^{\circ} \mathrm{C}$. It was apparent that the tribological performance at $120^{\circ} \mathrm{C}$ is inferior to that at $25^{\circ} \mathrm{C}$, which was caused by the failure of the oil film at high temperatures. From all the friction tests, we can conclude that the $\mathrm{C}+\mathrm{P}(1: 2)$ has the best tribological performance at all working conditions due to its relatively weak colloid stability, releasing more oil to the sliding interfaces. To summarize, the friction parameters have a significant influence on the tribological performance of asprepared grease. It is important to confirm the optimal working conditions for PUG formulations, which contribute to maximizing the lubrication

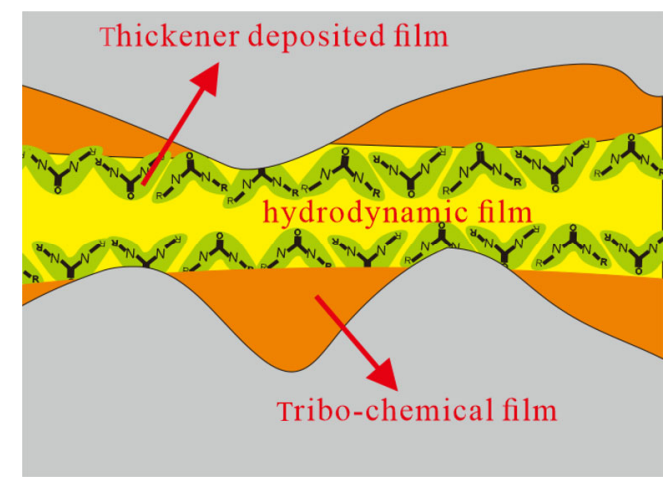

Fig. 13 Schematic diagram of tribological mechanism of as-prepared PUG. 
efficiency and improving the performance under harsh working conditions.

Although grease used for friction-reducing and anti-wear has made significant advances, the sealing function as a corrosion-resistant material has not yet been explored. Although the properties of base oils and additives have significant effects on the performance of greases, the thickener as an indispensable ingredient is often neglected. The thickeners with different structures and components largely determine the properties of grease. The thickener provides PUG with a certain consistency, which is regarded as sealing and anti-corrosive material. However, the corrosion resistance of PUG has not yet been explored. The thickener of PUG was regulated via different organic amines reacting with isocyanate to evaluate the performance characteristics (physicochemical properties, corrosion resistance, and tribological performance). The related friction and corrosion mechanism were analyzed by surface/interface analysis techniques (like SEM and XPS). The results illustrate that the formulation of $\mathrm{C}+\mathrm{P}$ exhibits the best comprehensive performance (such as physicochemical properties, tribological performance, and corrosion resistance). These performance characteristics contribute to long-term efficiency lubrication of modern/future mechanical equipment. The synergistic of greasefilm and tribo-chemical reaction film acts as the lubrication function in the lubrication boundary.

\section{Conclusions}

Twelve PUGs were successfully synthesized via regulating organic amines (including octadecylamine, cyclohexylamine, p-toluidine, and the combination of any two organic amines in the molar ratios of 1:2, 1:1, 2:1). Their physicochemical, salt spray resistance, and tribological properties were evaluated in detail. The conclusions are as follows:

1) The as-prepared PUGs have excellent physicochemical performance (high thermostability, high dropping point over $270{ }^{\circ} \mathrm{C}$, and excellent colloidal stability), illustrating that the thickener formulation can significantly impact the performance of the grease.
2) The as-prepared PUGs possess excellent corrosion resistance owing to good sealing function, thereby protecting the mechanical parts from corrosion under the complicated working conditions.

3) Comparing the tribological properties of these PUGs, the grease from the reaction of MDI and cyclohexylamine/p-toluidine in 1:2 provides the best friction reduction and wear resistance, as well as the load-carrying capacity. Confirming that the regulation of thickener formulation can improve the lubrication function of grease.

4) Although the abrasive wear of worn surfaces under PUG lubrication is a main failure form, excellent lubrication function of as-regulated PUG is largely dependent on the synergy of the grease (made up of oil-film and thickener-deposited film) and tribo-chemical films (composed of $\mathrm{FeOOH}$, $\mathrm{Fe}_{2} \mathrm{O}_{3}$, and nitrides).

Open Access This article is licensed under a Creative Commons Attribution 4.0 International License, which permits use, sharing, adaptation, distribution and reproduction in any medium or format, as long as you give appropriate credit to the original author(s) and the source, provide a link to the Creative Commons licence, and indicate if changes were made.

The images or other third party material in this article are included in the article's Creative Commons licence, unless indicated otherwise in a credit line to the material. If material is not included in the article's Creative Commons licence and your intended use is not permitted by statutory regulation or exceeds the permitted use, you will need to obtain permission directly from the copyright holder.

To view a copy of this licence, visit http://creativecommons.org/licenses/by/4.0/.

\section{References}

[1] Murkute P, Ramkumar J, Choudhary S, Mondal K. Effect of alternate corrosion and wear on the overall degradation of a dual phase and a mild steel. Wear 368-369: 368-378 (2016)

[2] Arora A K, Jaswal V S, Singh K, Singh R. Applications of metal/mixed metal oxides as photocatalyst: A review. Orient J Chem 32(4): 2035-2042 (2016) 
[3] Guo Z W, Yuan C Q, Bai X Q, Yan X P. Experimental study on wear performance and oil film characteristics of surface textured cylinder liner in marine diesel engine. Chin J Mech Eng 31(1): 52 (2018)

[4] Yeong S K, Luckham P F, Tadros T F. Steady flow and viscoelastic properties of lubricating grease containing various thickener concentrations. J Colloid Interface Sci 274(1): 285-293 (2004)

[5] Lugt P M. A review on grease lubrication in rolling bearings. Tribol Trans 52(4): 470-480 (2009)

[6] Lyadov A S, Maksimova Y M, Shakhmatova A S, Kirillov V V, Parenago O P. Urea (polyurea) greases. Russ J Appl Chem 91(6): 885-894 (2018)

[7] Kumar A, Humphreys S, Mallory B. Robust Polyurea grease for wide range of Industrial applications. In Proceedings of the 12th NLGI Lubricating Grease Conference on a Theme Lubricating Greases Challenges Ahea, Tulsa, Oklahoma, USA, 2010.

[8] Dai X Z, Guo P, Hong D M, Hui J D, Hui Z M, Geng F. The effect of preparation and characterisation of polyurea grease. Mater Res Innov 19: S5-588-S5-591 (2015)

[9] Venkataramani P S, Srivastava R G, Gupta S K. High temperature greases based on polyurea gellants: A review. J Synth Lubr 4(3): 229-244 (1987)

[10] Baum M W. High viscosity index PAO with polyurea thickeners in grease compositions. U. S. Patent 8772 210, Jul. 2014.

[11] Pratt S, Fliss E A. Polyurea grease composition. U. S. Patent 5238 589, Aug. 1993.

[12] Liu L, Sun H W. Impact of polyurea structure on grease properties. Lubr Sci 22(9): 405-413 (2010)

[13] Maksimova Y M, Shakhmatova A S, Ilyin S O, Pakhmanova O A, Lyadov A S, Antonov S V, Parenago O P. Rheological and tribological properties of lubricating greases based on esters and polyurea thickeners. Pet Chem 58(12): 1064-1069 (2018)

[14] Goncalves D, Graça B, Campos A V, Seabra J, Leckner J, Westbroek R. Formulation, rheology and thermal ageing of polymer greases-Part I: Influence of the thickener content. Tribol Int 87: 160-170 (2015)

[15] Salomonsson L, Stang G, Zhmud B. Oil/thickener interactions and rheology of lubricating greases. Tribol Trans 50(3): 302-309 (2007)

[16] Singh J, Kumar D, Tandon N. Rheological and film forming behavior of the developed nanocomposite greases under elastohydrodynamics lubrication regime. $J$ Tribol 141(2): 021804 (2019)

[17] Fischer D, Mues H, Jacobs G, stratmann A. Effect of over rolling frequency on the film formation in grease lubricated EHD contacts under starved conditions. Lubricants 7(2): 19 (2019)

[18] Gonçalves D E P, Campos A V, Seabra J H O. An experimental study on starved grease lubricated contacts. Lubricants 6(3): 82 (2018)

[19] Huang L, Guo D, Wen S Z. Starvation and reflow of point contact lubricated with greases of different chemical formulation. Tribol Lett 55(3): 483-492 (2014)

[20] Cousseau T, Björling M, Graça B, Campos A, Seabra J, Larsson R. Film thickness in a ball-on-disc contact lubricated with greases, bleed oils and base oils. Tribol Int 53: 53-60 (2012)

[21] Saatchi A, Shiller P J, Eghtesadi S A, Liu T B, Doll G L. A fundamental study of oil release mechanism in soap and non-soap thickened greases. Tribol Int 110: 333-340 (2017)

[22] Cyriac F, Lugt P M, Bosman R, Padberg C J, Venner C $\mathrm{H}$. Effect of thickener particle geometry and concentration on the grease EHL film thickness at medium speeds. Tribol Lett 61(2): 18 (2016)

[23] Xiong C H, Mi H Y, Feng Q, Wu B J. Comparative studies on low noise greases operating under high temperature oxidation conditions. China Pet Process Pe 16(4): 100-106 (2014)

[24] Lyadov A S, Maksimova Y M, Ilyin S O, Gorbacheva S N. Specific features of greases based on poly- $\alpha$-olefin oils with ureate thickeners of various structures. Russ $J$ Appl Chem 91(11): 1735-1741 (2018).

[25] Fan X Q, Xia Y Q, Wang L P, Pu J B, Chen T D, Zhang $\mathrm{H}$ B. Study of the conductivity and tribological performance of ionic liquid and lithium greases. Tribol Lett 53(1): 281-291 (2014)

[26] Liu D B, Zhao G Q, Wang X B. Tribological performance of lubricating greases based on calcium carbonate polymorphs under the boundary lubrication condition. Tribol Lett 47(2): 183-194 (2012)

[27] Yan J C, Zeng H, Liu T, Mai J H, Ji H B. Tribological performance and surface analysis of a borate calcium as additive in lithium and polyurea greases. Tribol Trans 60(4): 621-628 (2017)

[28] Zhang C X, Song Z Q, Liu Z F, Cheng Q, Zhao Y S, Yang C B, Liu M M. Wear mechanism of flexspline materials regulated by novel amorphous/crystalline oxide form evolution at frictional interface. Tribol Int 135: 335-343 (2019)

[29] Singh J, Kumar D, Tandon N. Tribological and vibration studies on newly developed nanocomposite greases under boundary lubrication regime. J Tribol 140(3): 032001 (2018)

[30] Kaneta M, Ogata T, Takubo Y, Naka M. Effects of a thickener structure on grease elastohydrodynamic lubrication films. Proc Inst Mech Eng Part J: J Eng Tribol 214(4): 327-336 (2000)

[31] Fan X Q, Li W, Li H, Zhu M H, Xia Y Q, Wang J J. Probing the effect of thickener on tribological properties 
of lubricating greases. Tribol Int 118: 128-139 (2018)

[32] Huang L, Guo D, Liu X, Xie G X, Wan G T Y, Wen S Z. Effects of Nano thickener deposited film on the behaviour of starvation and replenishment of lubricating greases. Friction 4(4): 313-323 (2016)

[33] Paszkowski M, Wróblewski R, Walaszczyk A. Studies of the influence of temperature and the energy state of the surface layer of adsorbents on wall effects in soap-based greases. Tribol Lett 65(1): 19 (2017)

[34] Czarny R, Paszkowski M, Knop P. The wall effect in the flow of commercial lubricating greases. J Tribol 138: 031803 (2016)

[35] Gonçalves D E P, Campos A V, Seabra J H O. An experimental study on starved grease lubricated contacts. Lubricants 6(3): 82 (2018)

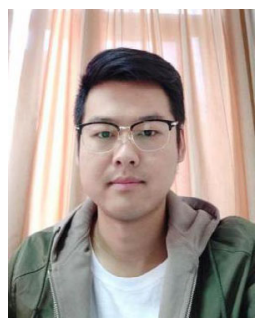

Guanlin REN. He obtained his bachelor degree from Shandong Jiaotong University, Jinan, China, in 2017. He is currently a graduate student in the School of Mechanical

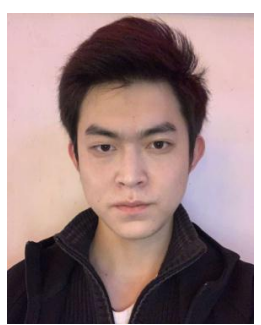

Xiaowen SUN. He is an undergraduate at Southwest Jiaotong

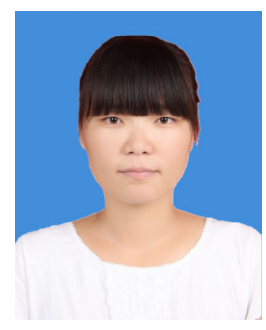

Wen LI. She is currently an associate professor at Southwest Jiaotong Unversity. She received her bachelor degree in 2011 from Liaocheng University, and a Ph.D.

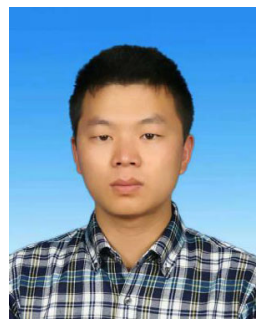

Hao LI. He is currently an instructor at Southwest Jiaotong University. He received his bachelor degree in 2011 from Lanzhou University, and a Ph.D. degree from
[36] Piet M L, Slavco V, John H T. On the chaotic behavior of grease lubrication in rolling bearings. Tribol Trans 52(5): 581 - 590 (2009)

[37] Wan S H, Tieu A K, Zhu Q, Zhu H T, Cui S G, Mitchel D R G, Kong C, Cowie B, Denman J A, Liu R. Chemical nature of alkaline polyphosphate boundary film at heated rubbing surfaces. Sci Rep 6(1): 26008 (2016)

[38] Wan S H, Tieu A K, Xia Y N, Wang L P, Li D S, Zhang G A, Zhu H T, Tran B H, Mitchell D R G. Tribochemistry of adaptive integrated interfaces at boundary lubricated contacts. Sci Rep 7(1): 9935 (2017)

[39] Vengudusamy B, Kuhn M, Rankl M, Spallek R. Film forming behavior of greases under starved and fully flooded EHL conditions. Tribol Trans 59(1): 62-71 (2016)

Engineering, Southwest Jiaotong University, China. His research interests include the design of lubricating materials and the tribological properties of lubricating grease.

University, China. His majors in materials science and engineering.

degree from Lanzhou Institute of Chemical Physics, Chinese Academy of Sciences, 2017. Her research interests cover nanoenergy materials, micronanodevices, optoelectronic devices, and micronanofabrication.

Lanzhou Institute of Chemical Physics, Chinese Academy of Sciences, 2016. His research interests cover solid lubricating coatings and the related tribological properties. 


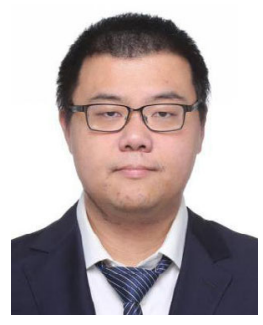

Lin ZHANG. He received his bachelor degree from Southwest Jiaotong Unversity. He is currently a postdoctoral student in the

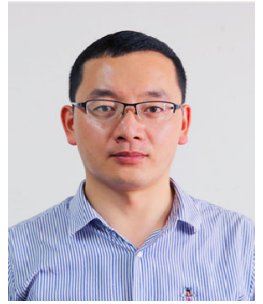

Xiaoqiang FAN. He is currently an associate professor at Southwest Jiaotong Unversity. He received his bachelor degree in 2011 from Qingdao University of Science \& Technology, and a Ph.D. degree

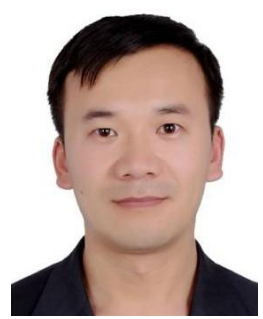

Dongshan LI. He is currently a research assistant at State Key Laboratory of Solid Lubrication, Lanzhou Institute of Chemical Physics, Chinese Academy of Sciences. He received his bachelor

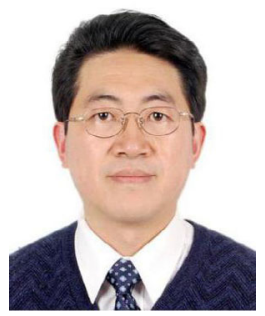

Minhao ZHU. He received his bachelor degree and master degree from Southwest Jiaotong University, China, in 1990 and 1993, respectively. He has been working at Southwest Jiaotong University since 1993. He received his Ph.D. degree from Southwest Jiaotong University, China, 2001. He is currently a professor, Cheung Kong Scholar, and
School of Mechanical Engineering, Southwest Jiaotong University. His research interests include the design of damping materials and the dynamic mechanical properties.

from Lanzhou Institute of Chemical Physics, Chinese Academy of Sciences, 2016. His research focuses on lubricating materials, corrosion protection, and engineering applications. He has published over 40 papers in international journals.

degree in 2009 from Hunan University of Science and Technology, master degree from Lanzhou Jiaotong University in 2014. His research interests cover surface treatment technology and solidliquid composites lubrication technology.

dean of School of Materials Science and Engineering. His research areas cover fretting wear, fretting fatigue, surface engineering, and design of fastener connections. He has published over 200 papers in international journals such as Carbon, Tribology International, Surface \& Coatings Technology, Tribology Letters, Wear, and Friction, etc., which have received more than 1,000 citations. 